\title{
International Journal of Engineering
}

Journal Ho m e page: w w w. i je.i r

\section{A New Mathematical Model for a Multi-product Supply Chain Network with a Preventive Maintenance Policy}

\author{
A. Fatehi-Kivia, E. Mehdizadeh ${ }^{\text {b }}$ R. Tavakkoli Moghaddam ${ }^{*, d}$ \\ a Department of Industrial Engineering, Science and Research Branch, Islamic Azad University, Tehran, Iran \\ ${ }^{b}$ Faculty of Industrial and Mechanical Engineering, Qazvin Branch, Islamic Azad University, Qazvin, Iran \\ c School of Industrial Engineering, South Tehran Branch, Islamic Azad University, Tehran, Iran \\ d Arts et Métiers ParisTech, LCFC, Metz, France
}

\section{$P A P E R \quad I N F O$}

\section{Paper history:}

Received 22 Febraury 2019

Received in revised form 12 September 2019

Accepted 12 September 2019

\section{Keywords:}

Genetic Algorithm

Harmony Search

Preventive Maintenance

Production-Distribution

Supply Chain Network Design

Tabu Search

\section{$A \begin{array}{llllllllllllll} & S & T & R & A & C & T\end{array}$}

The supply chain network design (SCND) implicates decision-making at a strategic level and makes it possible to create an effective and helpful context for managing. The aim of the network is to minimize the total cost so that customer's demands should be met. Preventive maintenance is pre-determined work performed to a schedule with the aim of preventing the wear and tear or sudden failure of equipment components. Unfortunately, there is very little work on the issues of preventive maintenance in the SCND. At first, a mixed integer nonlinear programming model (MINLP) is formulated that maximaize the profit of the network. Since the SCND is an NP-hard problem, we use three meta-heuristic algorithms, namely tabu search, harmony search and genetic algorithm to solve the given problem. Taguchi method is also used to adjust the significant parameters of the forgoing meta-heuristics and select the optimal levels of the influential factors for the better algorithm performance. The results of different numerical experiments endorse the effectiveness of the HS algorithm.

doi: $10.5829 /$ ije.2019.32.10a.14

\section{INTRODUCTION}

In the current competitive business environment, many factors can influence company's performance, but the most important factors are product and service quality, customers' satisfaction and low production and distribution costs. During the past decades there have been some interesting studies in the literature concerning the network design problem.

Jayaraman and Pirkul [1] proposed an integrated multi-plant, multi-product distribution model. Yan et al. [2] proposed a strategic production distribution model for supply chain design with consideration of bills of materials (BOM). Shen [3] presented a multi-commodity supply chain design problem. Amiri [4] developed a mixed integer programming model and provides an efficient heuristic solution procedure for this supply chain system problem. Nagurney [5] modeled the supply chain network design problem with oligopolistic firms who are involved in the competitive production, storage, and distribution of a homogeneous product to multiple demand markets.

Bashiri et al. [6] presented a new mathematical model for strategic and tactical planning in a multiple-echelon, multiple-commodity production-distribution network. Fahimnia et al. [7] proposed an integrated multi-period and multi-product production-distribution planning model to solve the integrated production-distribution planning problem. Khalifehzadeh et al. [8] proposed a mixed-integer linear (MIL) programming model for a four-echelon supply chain structure including multiple suppliers, multiple producers, multiple distributors and multiple customers. Fattahi et al. [9] addressed a new problem in designing and planning a multi-echelon and multi-product supply chain network over a multi-period horizon in which customer zones have price-sensitive demands. 
Taxakis and Papadopoulos [10] proposed two models. The first model is a mixed-integer linear programming model which is concerned with the SCN design problem, whereas the second operational model is a mixed-integer non-linear programming model in respect to the production-distribution and inventory planning problem in a supply chain network. Ardalan et al. [11] presented supply chain networks design with multi-mode demand satisfaction policy. In multi-mode demand satisfaction policy, some modes are defined by the customers and one of those must be satisfied by the network. The major advantages of this policy rather than prefixed demand are outstanding performance in facility capacity usage, increasing the profit of the network and market share preserving. Also they developed a new iterative Lagrangian relaxation based heuristic.

Preventive maintenance has many different variations and is subject of various researches to determine best and most efficient way to maintain equipment. Preventive maintenance (PM) has the following meanings: (1) The care and servicing by personnel for the purpose of maintaining equipment and facilities in satisfactory operating condition by providing for systematic inspection, detection, and correction of incipient failures either before they occur or before they develop into major defects. (2) Maintenance, including tests, measurements, adjustments, and parts replacement, performed specifically to prevent faults from occurring [12]. Israel et al. [13] proposed a method, which aims to integrate information provided by Intelligent Maintenance Systems into the operational planning of a spare parts supply chain.

The multi-stage logistic network considered in this paper consists of three stages: plants, distribution centers and retailer locations. The problem deals with determining the optimal transportation network with preventive maintenance in order to satisfy the retailer multi-mode demands of several products by using several kinds of vehicles with the maximum profit. Its assumed that there are $\mathrm{p}$ vehicle types for transportation with a limited budget for purchasing or hiring them. The capacity of vehicles and their fixed travel cost are taken into consideration. The capacity of plants and distribution centers and cost of production product $i$ on machines are taken into consideration too.

This paper considers the problem of the four-echelon supply chain network design (SCND) with a multi-mode demand satisfaction policy of retailers for multiple products and preventive maintenance with the maximum profit are defined. To this end, firstly the problem is defined with a mixed-integer non-linear programming model (MINLP) for integrated transportation and production in a supply chain. Then, three meta-heuristic algorithms, with a special chromosome structure is expanded to solve the problem.

The remaining of this article is organized as follows.
Section 2 the problem is described and a mathematical model is presented. The solution approaches for solving the proposed model introduced in section 3. Taguchi method for tuning the parameters and computational experiments is presented in section 4 . The conclusions and suggestions for future studies are included in section 5.

\section{MATHEMATICAL MODEL}

The logistics network discussed in this paper is a three stage logistics network including plants, distribution centers and retailers. The capacity of the sources and depots, the capacity of the vehicles, and the limited number of the vehicles are considered in this network. Mechanical, process or control equipment failure can have adverse results in both human and economic terms. Preventive maintenance, therefore, is a very important ongoing accident prevention activity, which you should integrate into your operations/ product manufacturing process.

\section{1. Assumptions In this section, we present a} MINLP model for the Multi-Product Multi-Stage Supply Chain Network with Preventive Maintenance. The assumptions of the model are as follows:

- The location of retailers and their demand modes are known in advance.

- One of these demand's mode for each retailer has to be satisfied by the distribution centers.

- The locations of plants and distribution centers are not predetermined and chosen from candidate options.

- Plants and distribution centers are capacitated.

- If maintenance is not performed in period $t$, the cost of maintenance will not apply to the model, the failure costs will be considered in period $t+1$ instead, and downtime will be deducted from available machine capacity.

- Transportation costs are based on the transportation cost of the products and using vehicles to carry products.

- The capacity of the vehicles, and the limited number of the vehicles are considered in this network.

\section{2. Parameters and Indices}

$\begin{array}{ll}i & \text { index of product, } i=\{1,2, \ldots, I\} . \\ j & \text { index of distribution centers, } j=\{1,2, \ldots, J\} . \\ k & \text { index of retailers, } k=\{1,2, \ldots, K\} . \\ m & \text { index of mode satisfaction, } m=\{1,2, \ldots, M\} \\ t & \text { index of periods, } t=\{1,2, \ldots, T\} \\ n & \text { index of machines, } n=\{1,2, \ldots, N\}\end{array}$


$p \quad$ index of vehicle, $p=\{1,2, \ldots, P\}$

$P r c_{i t} \quad$ Sale price of each unit of product $i$ in period $t$.

$V c p_{\text {int }} \quad$ Variable production cost of product $i$ on machine $n$ in period $t$. and in period $t$.

$C C P_{f t} \quad$ Fixed costs of establishing plant $f$ in period $t$.

$C C D C_{j t}$

Fixed cost of establishing distribution center $j$ in period $t$.

$C P_{f i t}$

Capacity of plant $f$ to production of product $i$ in period $t$.

$C W_{i j t}$

Capacity of distribution center $j$ of product $i$ in period $t$.

$C B_{n t} \quad$ Failure cost of machine $n$ in period $t$

$C M_{n t} \quad$ Cost of service to maintenance of machine $n$ in period $t$.

$C B_{p t} \quad$ Failure cost of vehicle $p$ in period $t$

$C M_{p t} \quad$ Cost of service to maintenance of vehicle $p$ in period $t$.

$M_{n t} \quad$ Time capacity of machine $n$ in period $t$

$M_{p t} \quad$ Time capacity of vehicle $p$ in period $t$

$E_{\text {in }} \quad$ Time required for the machine $\mathrm{n}$ to produce a unit of product $i$

$M \quad$ A large number

$M T_{n t} \quad$ Time of maintenance on mashine $n$ in period $t$

$M T_{p t} \quad$ Time of maintenance on vehicle $p$ in period $t$

Percentage of the capacity of machine $n$, lost during

$K_{n t} \quad$ period $t$ (due to lack of maintenance in the previous period) due to failure period $t$ (due to lack of maintenance in the previous period) due to failure

$\alpha_{p} \quad$ Distance traveled by the vehicle $p$ per hour

$C_{i t} \quad$ Cost of carrying each product $i$ during period $t$ per unit of distance

$D M_{f j} \quad$ Distance between plant $f$ and distribution center $j$

$D M_{j k} \quad$ Distance between distribution center $j$ and retailer $k$

$p u_{p t} \quad$ The cost of renting vehicle $p$ in period $t$

$C 1_{\text {pifit }} \quad$ Fixed cost of using vehicle $p$ to transport product $i$ from plant $f$ to distribution center $j$ in period $t$

$C 2_{p i j k t} \quad$ Fixed cost of using vehicle $p$ to transport product $i$ from distribution center $j$ to retailer $k$ in period $t$

$a_{p i}$

Capacity of vehicle $p$ to transport product $i$

$p u_{p t} \quad$ Cost of renting or purchasing vehicle $p$ in period $t$ $b_{p t} \quad$ Maximum budget available to buy or rent vehicle $p$ in period $t$

Total products $i$ transported from plant $f$ to distribution center $j$ in period $t$

Total products $i$ transported from distribution center $j$ to retailer $k$ in period $t$

The binary variable is equal to 1 if the demand for

$R_{i k t}^{m} \quad$ mode $\mathrm{m}$ from product $\mathrm{i}$ is answered by the retailer $k$ in period $t$, otherwise it will be 0

$P_{f t} \quad$ Binary variable equal to 1 if plant $\mathrm{f}$ is established in period $\mathrm{t}$, otherwise to 0

Binary variable equal to 1 if distribution center $\mathrm{j}$ is established in period $t$, otherwise to 0

$W_{j t} \quad$ Binary variable equal to 1 if preventive maintenance decision variable on machine $\mathrm{n}$ in period $\mathrm{t}$, otherwise to 0

Binary variable equal to 1 if preventive maintenance decision variable on vehicle $\mathrm{p}$ in period $\mathrm{t}$, otherwise to 0

Binary variable represents the type of vehicle $\mathrm{P}$

$P M_{p t} \quad$ chosen for product $\mathrm{i}$ from distribution center $\mathrm{j}$ to retailer $\mathrm{k}$ in period $\mathrm{t}$

Binary variable that represents the type of vehicle $p$ want to move product $i$ from factury $f$ to distribution center $\mathrm{j}$

Binary variable that represents the type of vehicle $p$

$B 2_{p i j k t} \quad$ want to move product $\mathrm{i}$ from distribution center $\mathrm{j}$ to retailr $\mathrm{k}$

2. 3. Mathematical Modeling The objective of this problem is to maximize the profit, which mathematically is written by:

$\operatorname{Max} \quad Z=\sum_{i} \sum_{k} \sum_{m} \sum_{t}\left(\left(\operatorname{Prc}_{i t}-\sum_{n} V c p_{i n t}\right) \cdot D_{i k t}^{m} \cdot R_{i k t}^{m}\right)-$

$\sum_{f} \sum_{t} C C P_{f t} \cdot P_{f t}+\sum_{j} \sum_{t} C C D C_{j t} W_{j t}+$

$\left(\sum_{n} \sum_{t} C B_{n, t} \cdot\left(1-P M_{n, t-1}\right)\right)+\left(\sum_{n} \sum_{t} C M_{n, t} \cdot P M_{n, t}\right)+$

$\left(\sum_{p} \sum_{t=2}^{T} C B_{p, t} \cdot\left(1-P M_{p, t-1}\right)\right)+\left(\sum_{p} \sum_{t=1}^{T-1} C M_{p, t} \cdot P M_{p, t}\right)+$

$\sum_{f} \sum_{i} \sum_{j} \sum_{t}\left(\sum_{p}\left(p u_{i j t}+C 1_{p j j t}\left(\frac{X_{i j t i t}}{a_{p i}}\right) \cdot B 1_{p i j t}\right)\right)+$

$\sum_{j} \sum_{i} \sum_{k} \sum_{t}\left(\sum_{p}\left(p u_{p t}+C 2_{p j k t} \cdot\left(\frac{Y_{i j k t}}{a_{p i}}\right) \cdot B 2_{p i j k t}\right)\right)$

s.t.

$\sum_{m} R_{i k t}^{m}=1 \quad \forall i, k, t$ 


$$
\begin{aligned}
& \sum_{j} Y i j k t=\sum_{m} R_{i k t}^{m} D_{i k t}^{m} \quad \forall i, k, t \\
& \sum_{f} X_{i f j t} \geq \sum_{k} Y_{i j k t} \quad \forall i, j, t \\
& \sum_{k} Y_{i j k t} \leq C W_{i j t} W_{j t} \quad \forall j, i, t
\end{aligned}
$$$$
\sum_{j} X_{i f j t} \leq C P_{f i t} \cdot P_{f t} \quad \forall i, t, f
$$$$
\mathrm{pu}_{\mathrm{pt}} \sum_{\mathrm{i}}\left(\sum_{\mathrm{f}} \sum_{\mathrm{j}} \mathrm{B} 1_{\mathrm{pift}}+\sum_{\mathrm{j}} \sum_{\mathrm{k}} \mathrm{B} 2_{\mathrm{pijkt}}\right) \leq \mathrm{b}_{\mathrm{pt}} \quad \forall \mathrm{t}, \mathrm{p}
$$$$
\mathrm{X}_{\mathrm{ifjt}} \leq \mathrm{M} \sum_{\mathrm{p}} \mathrm{B} 1_{\text {pifjt }} \quad \forall \mathrm{i}, \mathrm{f}, \mathrm{j}, \mathrm{t}
$$$$
\mathrm{Y}_{\mathrm{ijkt}} \leq \mathrm{M} \sum_{\mathrm{p}} \mathrm{B} 2_{\mathrm{pijkt}} \quad \forall \mathrm{i}, \mathrm{j}, \mathrm{k}, \mathrm{t}
$$$$
\sum_{\mathrm{p}} \mathrm{B}_{\mathrm{pifjt}} \leq 1 \quad \forall \mathrm{i}, \mathrm{f}, \mathrm{j}, \mathrm{t}
$$$$
\sum_{\mathrm{p}} \mathrm{B} 2_{\mathrm{pijkt}} \leq 1 \quad \forall \mathrm{i}, \mathrm{j}, \mathrm{k}, \mathrm{t}
$$

$\left(\sum_{\mathrm{i}} \mathrm{e}_{\mathrm{in}} \sum_{\mathrm{f}} \sum_{\mathrm{j}} \mathrm{X}_{\mathrm{ifjt}}\right)+\mathrm{PM}_{\mathrm{nt}} \mathrm{MT}_{\mathrm{nt}}$$$
+\left(1-\mathrm{PM}_{\mathrm{n}, \mathrm{t}-1}\right) \mathrm{K}_{\mathrm{nt}} \mathrm{M}_{\mathrm{nt}} \leq \mathrm{M}_{\mathrm{nt}}
$$$$
; \mathrm{t}=1, \ldots, \mathrm{T} \quad \mathrm{n}=1, \ldots, \mathrm{N}
$$$$
\begin{aligned}
& \left(\sum_{\mathrm{f}} \sum_{\mathrm{j}} \mathrm{DM}_{\mathrm{fj}}\left(\sum_{\mathrm{i}} \frac{\mathrm{X}_{\mathrm{ifjt}}}{\mathrm{a}_{\mathrm{pi}}}\right) \mathrm{B} 1_{\mathrm{pifjt}} /\right. \\
& \left.+\sum_{\mathrm{j}} \sum_{\mathrm{k}} \mathrm{DM}_{\mathrm{jk}}\left(\sum_{\mathrm{i}} \frac{\mathrm{Y}_{\mathrm{ijkt}}}{\mathrm{a}_{\mathrm{pi}}}\right) \mathrm{B} 2_{\mathrm{pijkt}}\right) / \alpha_{\mathrm{p}}
\end{aligned}
$$$$
+\mathrm{PM}_{\mathrm{pt}} \mathrm{MT}_{\mathrm{pt}}+\left(1-\mathrm{PM}_{\mathrm{p}, \mathrm{t}-1}\right) \mathrm{K}_{\mathrm{pt}} \mathrm{M}_{\mathrm{pt}} \leq \mathrm{M}_{\mathrm{pt}}
$$$$
; \mathrm{t}=1, \ldots, \mathrm{T} \quad \mathrm{p}=1, \ldots, \mathrm{P}
$$

$X_{i j j t}, Y_{i j k t} \geq 0 \quad \forall i, j, k, t, f$

$$
R_{i k t}^{m}, W_{j t}, P M_{n t}, P M_{p t}, P_{f t}, B 1_{p i j j t}, B 2_{p i j k t} \in\{0,1\}
$$$$
\forall i, j, m, p, k, t, n, f
$$

In the objective Function (1), maximizes total profit of the network. The first term is the total income of satisfied demands. The two subsequent terms are the fixed cost of opening plants and distribution centers, respectively. The Third terms is failure and maintenance costs of mashines and vehicles, respectivily. The forth terms represent the purchasing or hiring cost of vehicles and the travel cost of vehicles to carry products between the related sources and depots.

Constraint set (2) guarantees that for each retailer, one mode of demand satisfaction is selected. Constraint set (3) represents that transported each product from distribution centers to each retailer is equal to satisfied mode of retailer's demand. Constraint set (4) enforces that the total output of each distribution center is less than its total inputs.Constraint sets (5) and (6) ensure that the distributed products from each of the opened plants and distribution centers do not exceed their capacity limit. Constraint set (7) represents the budget constraints for purchasing or hiring vehicles. Constraint sets (8)-(9) enforce that there should be at least one kind of vehicle to carry products. Constraint sets (10)-(11) require that for each path and each product, only one kind of vehicle should be used. Constraint sets (12)-(13) The total amount of time needed to produce the product in the machine, maintenance time in the system and the reduced time of capacity due to system failure should be less than the available capacity of the machine and vehicle during the course. Constraints (14) and (15) place a binary and non-negativity restriction on the corresponding decision variables.

Defining new variables and adding some extra constraints as follows, non-linearity of the model can be eliminated.

$$
\begin{aligned}
& X_{i_{j j t}} \times B 1_{p_{i f j t}}=Z 1_{\text {pifjt }} \\
& Z 1_{\text {pif } j t} \geq X_{i f j t}-M\left(1-B 1_{\text {pifjt }}\right) \\
& Z 1_{\text {pifjt }} \leq X_{i f j t}+M\left(1-B 1_{\text {pifjt }}\right) \\
& Y_{i j k t} \times B 2_{\text {pijkt }}=Z 2_{\text {pijkt }} \\
& Z 2_{\text {pijkt }} \geq Y_{i j k t}-M\left(1-B 2_{\text {pijkt }}\right) \\
& Z 2_{\text {pijkt }} \leq Y_{i j k t}+M\left(1-B 2_{\text {pijkt }}\right)
\end{aligned}
$$

\section{SOLUTION CONCEPTS}

In this section, first the chromosome representation is described, and then metaheuristic algorithms are used to solve the problems. The notable advantage of a metaheuristic algorithm its ability in solving NP-hard problems. A number of authors [14-16] proposed metaheuristics to solve large-sized problems considering their computational time. Due to the NP-hardness of the proposed model, it is necessary to use a meta-heuristic approach to solve the proposed model. In this paper we 
use three meta-heuristic algorithms namely harmony search, tabu search and genetic algorithms. Table 1 show the Algorithm components and characters.

3. 1. Representation Scheme In this paper, the general structure of the solution representation performed for two products, two retailers, and two modes is shown in Figure 1. All algorithms are compiled in Visual Basic programming language. All computational tests are performed on a Dell not book at Intel Core2 Duo Processor $2 \mathrm{GHz}$ and $2 \mathrm{~GB}$ of RAM.

\section{COMPUTATIONAL RESULTS}

\section{1. Parameter Calibration}

In this section Taguchi method is employed to tune the parameters of the HS, GA and TS Algorithms, because the values of meta-heuristic algorithms parameters affected on quality of the solution. Taguchi method is a fractional factorial experiment proposed by Taguchi useable as an efficient alternative for full factorial experiments [17]. Table 2 lists different levels of the factors for HS, TS and GA. In this paper according to the levels and the number of the factors, respectively Taguchi method L27 for HS, GA and TS is used for the adjustment of the parameters for algorithms. Figures 2-4 show the $\mathrm{S} / \mathrm{N}$ ratios.

TABLE 1. Three algorithms and their components

\begin{tabular}{ll}
\hline Algorithm & Algorithm components and characters \\
\hline Genetic algorithm: the position crossover and swap \\
mutation for each stage and valid period; the initial \\
population is the diversification solution set DiverSet; \\
the evolution process stops if the best solution don't \\
be improved in continuous thirty generations. \\
Harmony search: Initialize the optimization problem \\
and algorithm parameters memory size (HMS); \\
harmony memory consideration rate (HMCR); pitch \\
adjusting rate (PAR) to apply HS. Improvise a new \\
harmony from the HM After defining the HM. Update \\
the HM. the evolution process stops if the best \\
solutions don't be improved in continuous thirty \\
generations. \\
Tabu search: swap neighborhood structure; the initial \\
solution is the best solution of the set DiverSet; the \\
search process stops if the solution don't be improved \\
in continuous thirty paces.
\end{tabular}

\begin{tabular}{|c|c|c|c|c|c|c|c|c|}
\hline \multirow{2}{*}{$R_{\mathrm{ikt}}^{\mathrm{m}}$} & \multicolumn{4}{|c|}{$\mathrm{T} 1$} & \multicolumn{4}{c|}{$\mathrm{T} 2$} \\
\cline { 2 - 9 } & \multicolumn{2}{|c|}{$\mathrm{i}=1$} & \multicolumn{2}{c|}{$\mathrm{i}=2$} & \multicolumn{3}{c|}{$\mathrm{i}=1$} & \multicolumn{2}{c|}{$\mathrm{i}=2$} \\
\hline $\mathrm{K}=1$ & 0 & 1 & 1 & 0 & 1 & 0 & 0 & 1 \\
\hline $\mathrm{K}=2$ & 0 & 1 & 1 & 0 & 1 & 0 & 0 & 1 \\
\hline
\end{tabular}

Figure 1. Solution representation
TABLE 2. Factors and their levels

\begin{tabular}{ccccc}
\hline Factor & Algorithm & Notation & Level & Value \\
\hline size of the tabu list & Tabu & $\mathrm{TL}$ & 3 & $6,12,18$ \\
Neighborhood size & & $\mathrm{NS}$ & 3 & $100,150,250$ \\
\hline $\begin{array}{c}\text { Pitch adjustment } \\
\text { rate }\end{array}$ & & $\mathrm{PAR}$ & 3 & $0.2,0.4,0.7$ \\
$\begin{array}{c}\text { Harmony memory } \\
\text { consideration rate }\end{array}$ & $\mathrm{HS}$ & $\mathrm{HMCR}$ & 3 & $0.1,0.5,0.9$ \\
$\begin{array}{c}\text { Harmony memory } \\
\text { size }\end{array}$ & & $\mathrm{HMS}$ & 3 & $10,30,50$ \\
Stop criteria & & $\mathrm{STOP}$ & 3 & $120,250,380$ \\
\hline $\begin{array}{c}\text { Number of } \\
\text { population }\end{array}$ & & $\mathrm{Npop}$ & 3 & $150,300,460$ \\
$\begin{array}{c}\text { Probability of } \\
\text { mutation }\end{array}$ & $\mathrm{GA}$ & $\mathrm{P}_{\mathrm{m}}$ & 3 & $0.1,0.8,0.95$ \\
$\begin{array}{c}\text { Probability of } \\
\text { crossover }\end{array}$ & & $\mathrm{P}_{\mathrm{c}}$ & 3 & $0.04,0.085,0.1$ \\
$\begin{array}{c}\text { Stronglymutation } \\
\text { Stop criteria }\end{array}$ & & $\mathrm{Sm}$ & 3 & $0.45,0.75,0.95$ \\
\hline
\end{tabular}

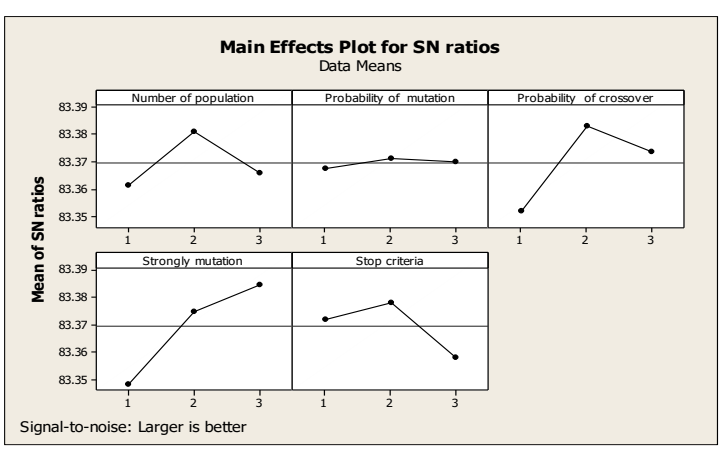

Figure 2. S/N ratio for the genetic algorithm

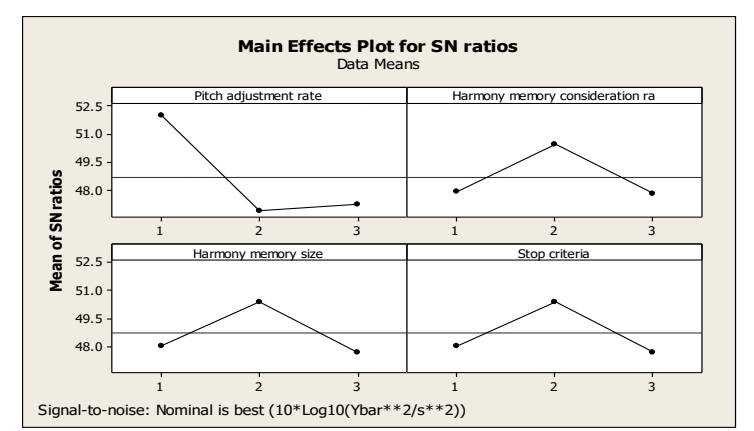

Figure 3. S/N ratio for the harmony search algorithm

\section{2. Numberical Results In this paper the test} instances are randomly generated based on the features of the integrated production-distribution planning problem. An instance is generated for each number of demand periods. Each instance is executed in ten runs. 


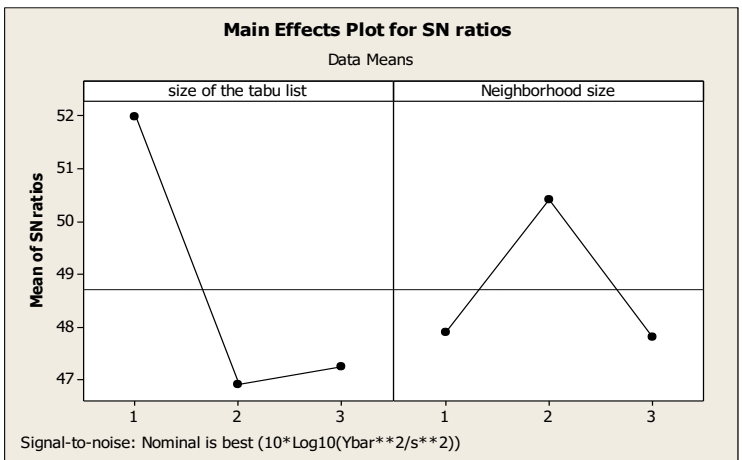

Figure 4. $\mathrm{S} / \mathrm{N}$ ratio for the tabu search algorithm

Computational experiments are conducted to validate and verify the behavior and the performance of the algorithms to solve the production and supply chain network model with preventive maintenance. Table 3 shows details of computational results obtained by solution methods for all test problems. We define 20

TABLE 3. Solution qualities of GA, HS and TS for each instance

\begin{tabular}{|c|c|c|c|c|}
\hline \multirow{2}{*}{ Pro. } & \multicolumn{4}{|c|}{ Objective function values } \\
\hline & $\left(\mathbf{n}_{\mathrm{i}}, \mathbf{n}_{\mathrm{f}}, \mathbf{n}_{\mathrm{j}}, \mathbf{n}_{\mathrm{k}}, \mathbf{n}_{\mathrm{m}}, \mathbf{n}_{\mathrm{t}}, \mathbf{n}_{\mathrm{n}}, \mathbf{n}_{\mathrm{p}}\right)$ & HS & TS & GA \\
\hline 1 & $(2,3,2,3,2,3,2,3)$ & 2916 & 2916 & 2916 \\
\hline 2 & $(2,3,4,4,3,3,3,4)$ & 4111.009 & 4111.009 & 4111.009 \\
\hline 3 & $(3,3,4,4,3,4,3,5)$ & 9282 & 9282 & 9282 \\
\hline 4 & $(3,4,4,5,3,4,3,6)$ & 11544 & 11544 & 11544 \\
\hline 5 & $(3,4,4,5,4,5,4,7)$ & 27156 & 26745 & 25184 \\
\hline 6 & $(4,4,5,5,4,5,3,8)$ & 10936.66 & 10936.66 & 10936.66 \\
\hline 7 & $(4,4,5,6,5,6,3,9)$ & 13414.46 & 12726.4 & 11276.55 \\
\hline 8 & $(4,4,5,6,5,7,4,10)$ & 16278.87 & 14183.32 & 14673.27 \\
\hline 9 & $(5,4,4,5,4,8,5,11)$ & 18309.55 & 17279.01 & 15734.82 \\
\hline 10 & $(6,5,5,6,6,9,6,12)$ & 22239.55 & 19407.85 & 16613.23 \\
\hline 11 & $(7,5,5,6,5,10,7,13)$ & 24398.67 & 21419.48 & 17723.56 \\
\hline 12 & $(7,6,6,7,6,11,8,14)$ & 26490.2 & 23845.2 & 18815.67 \\
\hline 13 & $(8,7,7,7,7,12,9,15)$ & 30061.12 & 26076.15 & 19388.26 \\
\hline 14 & $(9,7,8,8,8,13,10,16)$ & 33055.82 & 27361.91 & 21132.58 \\
\hline 15 & $(10,8,9,9,9,14,11,17)$ & 43055.82 & 41361.91 & 37132.58 \\
\hline 16 & $(11,8,10,10,9,15,12,18)$ & 47345.05 & 43401.38 & 40473.32 \\
\hline 17 & $(12,9,10,11,8,16,13,19)$ & 53727.24 & 47462.00 & 41704.98 \\
\hline 18 & $(13,9,11,12,10,17,14,20)$ & 58332.91 & 52836.99 & 44274.81 \\
\hline 19 & $(14,10,12,8,11,18,15,21)$ & 63996.14 & 58313.56 & 47233.87 \\
\hline 20 & $(15,10,14,11,12,19,16,22)$ & 77732.40 & 65498.02 & 49870.75 \\
\hline
\end{tabular}

instances that can be characterized by the number of products $\left(\mathrm{n}_{\mathrm{i}}\right)$ that are between 2 and 15 , plants $\left(\mathrm{n}_{\mathrm{f}}\right)$ that between 2 and 14, retailers $\left(n_{k}\right)$ that are between 2 and 11 , satisfactions mode $\left(\mathrm{n}_{\mathrm{m}}\right)$ that are between 2 and 12, periods $\left(n_{t}\right)$ that are between 2 and 19, machines $\left(n_{n}\right)$ that are between 2 and 16 , vehicle $\left(n_{p}\right)$ that are between 3 and 22. The objective function values listed in Table 3 are the average values in the ten runs for each instance. Table 4 shows the CPU time of three algorithms in each instance. In Tables 5 and 6 , according to the values of the survey (or $P$-Value) we can get the conclusion that the algorithm HS has the best solution quality in each instance between the three algorithms. To clarify the matter, the one-way analysis of variance (ANOVA) was used to compare the performances and CPU time for different sizes have been illustrated in tables and Figures 5 and 6 . The objective function value obtained by HS is bigger than that of the other two algorithms in each instance. TS and GA are the second and third best algorithms for solution quality, respectively and for cpu time the incremental sequence is HS, TS and GA according to the computational time.

TABLE 4. CPU time of GA, HS andTS for each instance

\begin{tabular}{|c|c|c|c|c|}
\hline \multirow{2}{*}{ Pro. } & \multicolumn{4}{|c|}{ Objective function values } \\
\hline & $\left(\mathbf{n}_{\mathrm{i}}, \mathbf{n}_{\mathrm{f}}, \mathbf{n}_{\mathrm{j}}, \mathbf{n}_{\mathrm{k}}, \mathbf{n}_{\mathrm{m}}, \mathbf{n}_{\mathrm{t}}, \mathbf{n}_{\mathrm{n}}, \mathbf{n}_{\mathrm{p}}\right)$ & HS & TS & GA \\
\hline 1 & $(2,3,2,3,2,3,2,3)$ & 4.09 & 3.26 & 2 \\
\hline 2 & $(2,3,4,4,3,3,3,4)$ & 12.45 & 17.98 & 20.81 \\
\hline 3 & $(3,3,4,4,3,4,3,5)$ & 15.77 & 65.71 & 79.99 \\
\hline 4 & $(3,4,4,5,3,4,3,6)$ & 49.73 & 103.11 & 127.29 \\
\hline 5 & $(3,4,4,5,4,5,4,7)$ & 108.95 & 153.85 & 191.65 \\
\hline 6 & $(4,4,5,5,4,5,3,8)$ & 142.10 & 346.36 & 436.14 \\
\hline 7 & $(4,4,5,6,5,6,3,9)$ & 195.82 & 379.47 & 458.06 \\
\hline 8 & $(4,4,5,6,5,7,4,10)$ & 296.26 & 677.36 & 871.28 \\
\hline 9 & $(5,4,4,5,4,8,5,11)$ & 323.20 & 889.19 & 1127.35 \\
\hline 10 & $(6,5,5,6,6,9,6,12)$ & 443.49 & 1382.16 & 1705.63 \\
\hline 11 & $(7,5,5,6,5,10,7,13)$ & 706.40 & 1356.82 & 1893.54 \\
\hline 12 & $(7,6,6,7,6,11,8,14)$ & 750.40 & 1668.12 & 1996.62 \\
\hline 13 & $(8,7,7,7,7,12,9,15)$ & 977.88 & 2210.56 & 2762.12 \\
\hline 14 & $(9,7,8,8,8,13,10,16)$ & 1667.10 & 2402.24 & 2885.32 \\
\hline 15 & $(10,8,8,9,9,14,11,17)$ & 1659.51 & 2295.54 & 2839.21 \\
\hline 16 & $(11,8,10,10,9,15,12,18)$ & 2348.73 & 2487.22 & 2962.41 \\
\hline 17 & $(12,9,10,11,8,16,13,19)$ & 2576.21 & 3029.66 & 3727.91 \\
\hline 18 & $(13,9,11,12,10,17,14,20)$ & 2620.21 & 3340.96 & 3830.99 \\
\hline 19 & $(14,10,12,8,11,18,15,21)$ & 2740.50 & 3315.62 & 4018.90 \\
\hline 20 & $(15,10,14,11,12,19,16,22)$ & 2767.44 & 3808.59 & 4597.18 \\
\hline
\end{tabular}




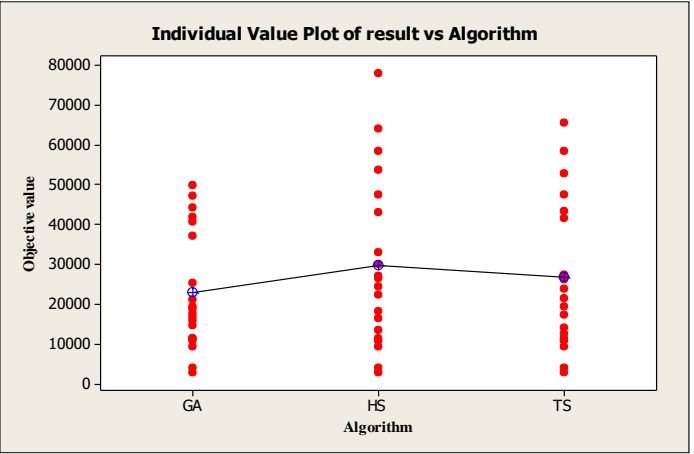

Figure 5. Individual value plot of objective values

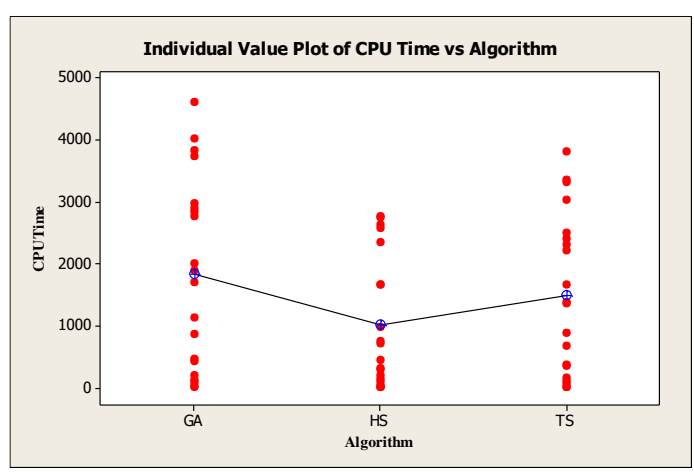

Figure 6. Individual value plot of CPU time

TABLE 5. Analysis of variance for objective values

\begin{tabular}{lccccc}
\hline Source & DF & SS & MS & F & P \\
\hline Result & 2 & 454337252 & 227168626 & 0.67 & 0.514 \\
Error & 57 & 19237651393 & 337502656 & & \\
Total & 59 & 19691988645 & & & \\
\hline
\end{tabular}

TABLE 6. Analysis of variance for CPU time

\begin{tabular}{lccccc}
\hline Source & DF & SS & MS & F & P \\
\hline Result & 2 & 6574329 & 3287165 & 1.92 & 0.156 \\
Error & 57 & 97502088 & 1710563 & & \\
Total & 59 & 104076417 & & & \\
\hline
\end{tabular}

\section{CONCLUSION}

In this paper, a model for Multi-product Supply Chain Network with a Preventive Maintenance Policy was investigated. The distinguished benefits of the mathematical model were as follows: supply chain network with multiple factories, multiple distributors, multiple retailers and multi-mode demand satisfaction policy with preventive maintains also Decision makers need to determine the optimal routes and vehicles when there is a limited budget for hiring vehicles. In this study, we formulated the problem as a mixed integer nonlinear programming model (MINLP) to maximize the total profit. To solve the proposed model, three meta heuristic algorithms namely HS, GA and TS was employed. Furthermore, an extensive parameter setting with performing Taguchi method was conducted for selecting the optimal levels of the factors that effect on the algorithm's performance. The results of the algorithms showed that the HS algorithm had a better performance than the GA and TS in terms of the objective function on 20 generated random problems. The one-way analysis of variance (ANOVA) was used to compare the performances of the HS, GA and TS algorithms statistically but HS had big time than GA and TS. Also, the tendency displayed that HS had better performances in comparison with GA and TS in most problems. Some of the opportunities for future research are as using the other meta-heuristic algorithms and extending the model with probability parameters.

\section{REFERENCES}

1. Jayaraman, V. and Pirkul, H., "Planning and coordination of production and distribution facilities for multiple commodities", European Journal of Operational Research, Vol. 133, No. 2, (2001), 394-408.

2. Yan, H., Yu, Z. and Cheng, T.E., “A strategic model for supply chain design with logical constraints: formulation and solution", Computers \& Operations Research, Vol. 30, No. 14, (2003), 2135-2155.

3. Shen, Z. J.M., "A multi-commodity supply chain design problem", Iie Transactions, Vol. 37, No. 8, (2005), 753-762.

4. Amiri, A., "Designing a distribution network in a supply chain system: Formulation and efficient solution procedure", European Journal of Operational Research, Vol. 171, No. 2, (2006), 567576.

5. Nagurney, A., "Supply chain network design under profit maximization and oligopolistic competition", Transportation Research Part E: Logistics and Transportation Review, Vol. 46, No. 3, (2010), 281-294.

6. Bashiri, M., Badri, H. and Talebi, J., "A new approach to tactical and strategic planning in production-distribution networks", Applied Mathematical Modelling, Vol. 36, No. 4, (2012), 17031717.

7. Fahimnia, B., Farahani, R.Z. and Sarkis, J., "Integrated aggregate supply chain planning using memetic algorithm-A performance analysis case study", International Journal of Production Research, Vol. 51, No. 18, (2013), 5354-5373.

8. Khalifehzadeh, S., Seifbarghy, M. and Naderi, B., "A fourechelon supply chain network design with shortage: Mathematical modeling and solution methods", Journal of Manufacturing Systems, Vol. 35, (2015), 164-175.

9. Fattahi, M., Mahootchi, M., Govindan, K. and Husseini, S. M. M., "Dynamic supply chain network design with capacity planning and multi-period pricing", Transportation Research Part E: Logistics and Transportation Review, Vol. 81, (2015), 169-202.

10. Taxakis, K. and Papadopoulos, C., "A design model and a production-distribution and inventory planning model in multiproduct supply chain networks", International Journal of Production Research, Vol. 54, No. 21, (2016), 6436-6457.

11. Ardalan, Z., Karimi, S., Naderi, B. and Khamseh, A. A., "Supply 
chain networks design with multi-mode demand satisfaction policy", Computers \& Industrial Engineering, Vol. 96, (2016), $108-117$.

12. Mehdizadeh, E. and Atashi-Abkenar, A.A., "An integrated aggregate production planning model with two-phase production system and maintenance costs", International Journal of Applied Operational Research, Vol. 4, (2014), 87-106.

13. Israel, E.F., Albrecht, A., Frazzon, E.M. and Hellingrath, B., "Operational supply chain planning method for integrating spare parts supply chains and intelligent maintenance systems", IFACPapersOnLine, Vol. 50, No. 1, (2017), 12428-12433.
14. Glover, F., "Future paths for integer programming and links to artificial intelligence", Computers \& operations research, Vol. 13, No. 5, (1986), 533-549.

15. Geem, Z.W., Kim, J.H. and Loganathan, G. V., "A new heuristic optimization algorithm: harmony search", Simulation, Vol. 76, No. 2, (2001), 60-68.

16. Sampson, J. R., "Adaptation in Natural and Artificial Systems (John H. Holland)”, SIAM Review, Vol. 18, No. 3, (1976), 529530 .

17. Taguchi, G., Chowdhury, S. and Taguchi, S., "Robust engineering (Vol. 224)", New York: McGraw-Hill, (2000).

\title{
A New Mathematical Model for a Multi-product Supply Chain Network with a Preventive Maintenance Policy
}

\author{
A. Fatehi-Kivia, E. Mehdizadeh ${ }^{\text {b }}$ R. Tavakkoli Moghaddam,d \\ ${ }^{a}$ Department of Industrial Engineering, Science and Research Branch, Islamic Azad University, Tehran, Iran \\ ${ }^{b}$ Faculty of Industrial and Mechanical Engineering, Qazvin Branch, Islamic Azad University, Qazvin, Iran \\ ${ }^{c}$ School of Industrial Engineering, South Tehran Branch, Islamic Azad University, Tehran, Iran \\ ${ }^{\mathrm{d}}$ Arts et Métiers ParisTech, LCFC, Metz, France
}

\section{PAPER IN FO}

Paper history:

Received 22 Febraury 2019

Received in revised form 12 September 2019

Accepted 12 September 2019

\section{Keywords:}

Genetic Algorithm

Harmony Search

Preventive Maintenance

Production-Distribution

Supply Chain Network Design

Tabu Search

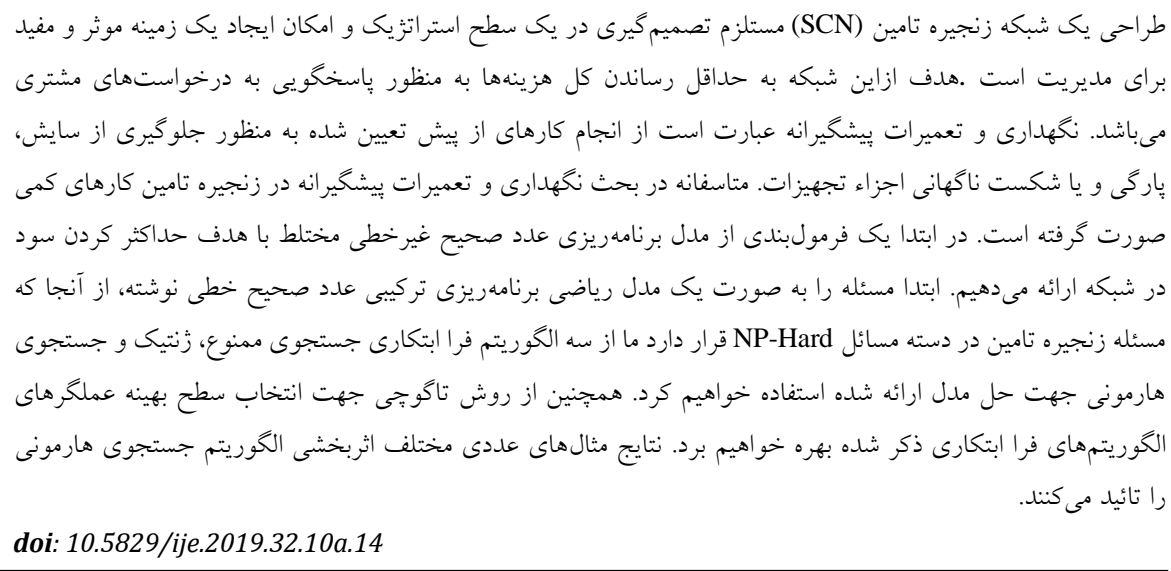

